Article

\title{
Disinformation in Facebook Ads in the 2019 Spanish General Election Campaigns
}

\author{
Lorena Cano-Orón ${ }^{1, *}$, Dafne Calvo ${ }^{2}$, Guillermo López García ${ }^{1}$ and Tomás Baviera ${ }^{3}$ \\ ${ }^{1}$ Department of Language Theory and Communication Sciences, University of Valencia, 46010 Valencia, Spain; \\ E-Mails: Iorena.cano@uv.es (L.C.-O.), guillermo.lopez@uv.es (G.L.G.) \\ 2 Department of Early Modern History, Modern History and History of America, Journalism and Audiovisual \\ Communication and Advertising, University of Valladolid, 47007 Valladolid, Spain; E-Mail: dafne.calvo@uva.es \\ ${ }^{3}$ Department of Economics and Social Sciences, Universitat Politècnica de València, 46022 Valencia, Spain; \\ E-Mail: tobapui@upv.es
}

* Corresponding author

Submitted: 11 June 2020 | Accepted: 10 August 2020 | Published: 3 March 2021

\begin{abstract}
As fake news elicits an emotional response from users, whose attention is then monetised, political advertising has a significant influence on its production and dissemination. Facebook ads, therefore, have an essential role in contemporary political communication, not only because of their extensive use in international political campaigns, but also because they address intriguing questions about the regulation of disinformation on social networking sites. This research employs a corpus of 14,684 Facebook ads published by the major national political parties during their campaigns leading up to the two Spanish general elections held in 2019. A manual content analysis was performed on all the visually identical ads so as to identify those containing disinformation and those denouncing it. The topics addressed in these ads were then examined. The results show that the political parties' Facebook ad strategies were akin to those of conventional advertising. Disinformation messages were infrequent and mainly posted by Ciudadanos and VOX. Nonetheless, it is striking that the main topic addressed in the ads was the unity of Spain-precisely the issue of Catalonia's independence. In light of this, it can be deduced that 'traditional' parties are taking longer to renounce classical forms of campaigning than their 'new' counterparts, thus demonstrating that the actors implementing disinformation strategies are not only restricted to the extreme right of the ideological spectrum.
\end{abstract}

\section{Keywords}

campaigns; disinformation; elections; Facebook; fake news; political communication; political parties; Spain

\section{Issue}

This article is part of the issue "Disinformation and Democracy: Media Strategies and Audience Attitudes," edited by Pere Masip (University Ramon Llull, Spain), Bella Palomo (University of Malaga, Spain) and Guillermo López (University of Valencia, Spain).

(C) 2021 by the authors; licensee Cogitatio (Lisbon, Portugal). This article is licensed under a Creative Commons Attribution 4.0 International License (CC BY).

\section{Introduction}

The phenomenon of digital disinformation has become particularly relevant in recent years, not only due to its widespread use in many countries (Bradshaw \& Howard, 2019), but also because of the Internet's capacity to amplify it, which, in turn, has repercussions for political life insofar as it undermines reliable information sources
(Benkler, Faris, \& Roberts, 2018; Bennett \& Livingston, 2018). Although some of those repercussions are unforeseen, others are clearly intentional. Campaigns of this sort are mainly launched on social networking sites such as Facebook, Twitter, Instagram and WhatsApp, and the main techniques are based on the use of bots (automated accounts that mimic human behaviour) and trolls (fake accounts managed by humans with specific intentions; 
Bradshaw \& Howard, 2019). Actually, it is not easy to identify who promotes these campaigns, although there are always political interests behind them.

Political parties are also active on social media. They post content like any other user, but also leverage advertising techniques, inserting sponsored content in news feeds in order to take advantage of the microtargeting capabilities of social media. Due to the Cambridge Analytica scandal, Facebook made sponsored content available to any user through its Facebook Ad Library (Hern, 2018), thus allowing the public to scrutinise the paid messages posted by political parties on this social networking site. As such content was inaccessible only a few years ago, research on digital disinformation has yet to explore political advertising on Facebook.

Some of the first elections to be called after this disclosure were held in Spain, specifically general elections on 28 April and 10 November 2019. So the election campaigns running up to them were preceded by the disinformation scandals in the United States, the United Kingdom and Brazil. Studies of this electoral cycle have revealed that disinformation was mainly spread via Twitter, Facebook and WhatsApp (Paniagua Rojano, Seoane Pérez, \& Magallón-Rosa, 2020; Rodríguez-Fernández, 2020).

Accordingly, the aim of this article is to contribute to the research on digital disinformation by analysing the messages conveyed by the major Spanish political parties in the 2019 general election campaigns, using the Facebook Ads tool. The main research question posed here is whether or not those parties implemented any disinformation strategy as regards their sponsored content on Facebook. As far as can be gathered from the literature, the dissemination of political disinformation via Facebook advertising is still an uncharted research avenue. Whereby the originality of this study, whose purpose is to fill that research gap, lies in the fact that it is presumably the first to focus on the Facebook Ads Library.

The presence of disinformation in the advertising messages of the major political parties in Spain, albeit rather thin on the ground, is by no means a minor object of study, inasmuch as those posting them have a lot to gain from this in the political contest. Even though Spanish political ads are by and large conventional, the findings of this study suggest they can include false information with an eye to manipulating public opinion.

This article is structured as follows. First, the theoretical framework is developed, distinguishing between several concepts relating to disinformation, such as fake news and propaganda. This is followed by a description of how the 14,684-ad database was created and of the content analysis methodology employed. Lastly, the findings are presented and discussed.

\section{Theoretical Framework}

The development of computational techniques for content creation and distribution (Tucker, Theocharis,
Roberts, \& Barberá, 2018) has contributed to place disinformation at the centre of political processes at an international level. The growing academic literature has explored disinformation operations in diverse contexts and at different hierarchical levels. This is the case of the use of Twitter by the president of the United States, Donald Trump (Marwick \& Lewis, 2017; Ross \& Rivers, 2018); the use of bots during the French presidential elections (Ferrara, 2017); the distribution of emotional and polarised information in the United Kingdom during the Brexit referendum campaign (Bastos \& Mercea, 2018; Cervi \& Carrillo-Andrade, 2019); the referendum on self-determination in Catalonia (Stella, Ferrara, \& De Domenico, 2018); and the recent publication of false information on Covid-19 in order to bolster Jair Bolsonaro's leadership (Ricard \& Medeiros, 2020). All these processes have highlighted the crucial role played by reliable information in any democratic system. Consequently, terms such as disinformation, fake news or even propaganda have entered into the public debate on politics. Nevertheless, these concepts are not easy to distinguish, as they are used in different ways in diverse scenarios (Magallón-Rosa, 2019).

There still is not a unanimous consensus on the definition of fake news. After the popularisation of this expression by the media, the concept has become even more vague (Bennett \& Livingston, 2018; Ireton \& Posetti, 2018). In their review of the academic literature on fake news, Tandoc, Lim, and Ling (2018) discovered that the term was indeed used to define up to six different types: news satire, news parody, fabrication, manipulation, advertising and propaganda. In addition to the efforts that have been made to identify and describe the disinformation tactics of parties and public authorities, some authors have contributed to research on this phenomenon by establishing taxonomies that, as analytical tools, shed light on the boundaries between propaganda and disinformation. These notions have been considered to be interchangeable by some authors, as is the case with the terms propaganda and publicity (Tandoc et al., 2018). According to Woolley and Howard (2016, p. 4886):

Computational propaganda involves software programs that are interactive and ideologically imbued....They are ideological, first, in that they are programmed to promote a particular perspective in politically charged conversations and, second, in that they are artifactual evidence of the idea that technology can be used to influence politics.

For Jack (2017), propaganda is a pejorative term per se, as opposed to other concepts such as advertising, public relations and public diplomacy. The first term refers to a deliberate intention to manipulate or deceive, which "can refer to political communications, advertising, and even junk mail" (Jack, 2017, p. 7).

The epistemological difficulty in differentiating between disinformation and propaganda stems from 
two of the main characteristics that both concepts share: the hyperpolarisation of their content and their creation for political purposes (Nielsen \& Graves, 2017). Therefore, although it cannot be called fake news in the strict sense of the word, information released by governments, public agencies and parties reflects their agendas in a way that differs from that of objective and evidence-based information (Molina, Sundar, Le, \& Lee, 2019). Propaganda and advertising include information that is usually based on facts, but with a bias that helps to present the propagandist or advertiser in a favourable light. The use of native advertising for disseminating this type of content makes it seem more credible, due to its similarity to other media publications or social media posts (Tandoc et al., 2018). In contrast, disinformation is a phenomenon that deliberately seeks to confuse the receiver with false or misleading information, with the aim of achieving persuasive goals or discrediting an opponent. Disinformation, from this perspective, can be regarded as a powerful propaganda tool (Benkler et al., 2018; Martin, 1982). Following Bennett and Livingston's (2018) reasoning, the phenomenon of fabricating and disseminating intentionally false information will be referred to here as disinformation. The intention is to convey its complexity, focusing not only on false information per se, but also on the strategies behind it.

This grey area between disinformation, propaganda and advertising evinces the complexity of this phenomenon in contemporary political processes. It gives a good account of the multiple and sophisticated tactics that are deployed to gain control of the narrative and to manipulate the electorate (Marwick \& Lewis, 2017). Such tactics have given rise to a broad debate on their shortand long-term effects on democratic systems, whose legitimacy is currently being questioned, reflected in a decline in the credibility of politicians and public institutions in the eyes of the public at large (Bennett \& Livingston, 2018; Tucker et al., 2018).

In this complex digital landscape, social media advertising has been operating as an opaque way to disseminate information. Through these tools, companies can send their ads to specific social media audiences in such a way that only they view the message (Tufekci, 2015; Woolley \& Howard, 2018). The capacity of social networking sites to segment audiences is based on the rich digital footprint left by users on them (Kim et al., 2018; Sinclair, 2016). In this vein, several researchers have raised the need to act on sponsored content owing to its potential to disseminate disinformation (Gray, Bounegru, \& Venturini, 2020). Particularly in the case of Facebook, some scholars have shown how this platform has been used to divide the population and to misinform, specifically in the case of ads paid for by Russia's Internet Research Agency in the United States (Lukito, 2020; Ribeiro et al., 2019).

Social networking sites are very appealing to advertisers. The business model of these sites, of which Facebook is the paradigm, has been built on their ad services (Dommett \& Power, 2019; Kreiss \& McGregor, 2018). Not only companies but also political parties' figure among their advertisers. However, the Cambridge Analytica scandal obliged Facebook to modify some of its practices. This social networking site decided, among other things, to put an end to the lack of transparency of the content sponsored by political parties. Accordingly, in April 2018 the Facebook Ad Library was launched with the aim of offering the public access to the paid messages of political parties being disseminated in its news feed (Hern, 2018).

This issue of social media accountability forms part of a broader debate on seeking solutions to an increasingly polarised, uninformed, and fragmented networking ecosystem (Bakir \& McStay, 2018). These sceptical views ultimately beg the question of the extent to which genuine civic engagement with democratic systems can be ensured on platforms that, as in the case of Facebook, rely on user metrics and the imperatives of advertising to turn a profit (Jack, 2017). The aim of this article is to offer an answer to this research question by focusing on the role played by political parties as clients of Facebook and how they address the controversial issue of disinformation.

\section{Methodology}

The object of study were the ads posted on Facebook by the Spanish Socialist Workers' Party (hereinafter PSOE), the People's Party (hereinafter PP), Ciudadanos, Unidas Podemos-a coalition between Podemos and United Left (hereinafter IU)-and VOX, the five parties with the best election prospects, during the pre- and election campaigns running up to the two general elections held in Spain in 2019 (on 28 April and 10 November). In order to perform an in-depth analysis on the kind of strategies that they were implementing, it was decided to consider Podemos and IU separately because their Facebook ads were mainly posted on their party pages, rather than on the coalition page.

The corpus was obtained through a web crawler written in Python. The Facebook Ad Library displays the ads paid for by a particular organisation in grid-format. This initial presentation provides the basic content of the ads with a link to access the metadata. This metadata, which is displayed on a new webpage, includes run time, advertiser spend, impressions and basic demographic segmentation, namely, sex, age, and autonomous community (geographical region). The first three metadata sets are shown in text format, while the last three are provided in image files. The crawler visited the library page of each political party and, after verifying that the ads corresponded to the two general elections under study, accessed each one of the ad metadata webpages, before downloading the content (text and image/video) and the metadata (text and image files) of the ad in question.

The corpus was made up of 14,684 ads (see Table 1 for their distribution by political party). As the Facebook 
Table 1. Information on the ads making up the corpus.

\begin{tabular}{lrrr}
\hline Political Party & No. ads & Estimated spend $(€)$ & Estimated impressions \\
\hline Ciudadanos & 8,560 & 584,100 & $70,436,500$ \\
IU & 18 & 4,750 & $1,207,500$ \\
PP & 4,517 & 489,350 & $60,235,500$ \\
Podemos & 924 & 995,100 & $129,992,000$ \\
PSOE & 621 & 69,350 & $22,767,500$ \\
VOX & 44 & 2,800 & 881,500 \\
\hline Total & 14,684 & $2,145,450$ & $285,520,500$ \\
\hline
\end{tabular}

Ad Library only provides ranges of values, the data on advertiser spend and impressions were not exact figures. To facilitate comparisons, ad spend, and impressions were estimated, taking into account the mean value of the range. For example, if the spend range of an ad was $€ 100-€ 499$, its mean value $€ 300$ was taken. The same procedure was used to calculate ad impressions. As a result, it was estimated that the five political parties spent approximately $€ 2$ million on the two election campaigns, with roughly 286 million impressions. Ciudadanos and the PP were the two parties posting the highest number of ads, while Podemos and Ciudadanos made the largest investment.

Although the data are presented here in an aggregated manner, it should be explained that the number of ads posted in both campaigns was not proportional (see Figure 1). This might have been owing to the fact that the campaign for the 10 November elections lasted half as long as that for the 28 April elections, due to both a Spanish law limiting the campaign period for repeated general elections and the more austere cam- paigns designed by all the parties after a year replete with election calls in Spain.

Following an initial data analysis, it was noted that there were numerous repetitions in the ad content. This was due to the microtargeting capabilities of Facebook: The same content was used in multiple ads, each with a different sociodemographic audience profile, which will be referred to hereinafter as 'visually identical ads' (VIAs). They cannot be regarded as mere duplicates because, albeit with the same content, each VIA had a different target audience (e.g., users in specific geographical locations), spend and number of impressions. Each ad formed part of a complex communication strategy aimed at engaging a predetermined Facebook audience with a particular discourse. To perform the analysis, only these VIAs $(1,743)$ were used.

Two variables were defined for the content analysis. The first is the type of information contained in the ads, which fell into the following two categories: 1 ) does not contain facts (generic calls to vote or election promises); 2 ) reports disinformation (the party presents itself as a

10.000

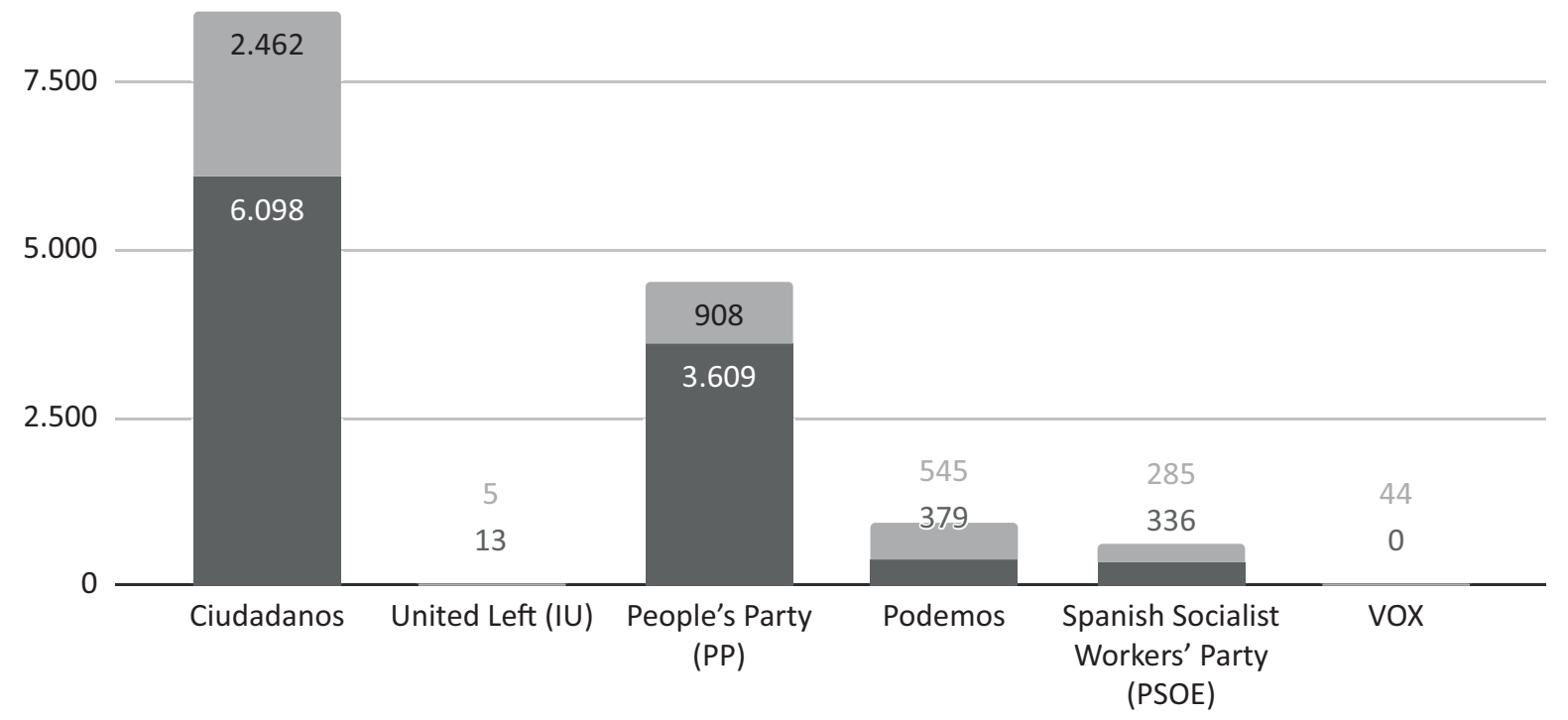

Figure 1. Ads posted by the parties during the 28 April and 10 November election campaigns (2019). 
victim of disinformation, manipulated by the media or its political rivals); 3) contains disinformation (when ad content is misleading or directly false); 4) and contains facts (their interpretation may sometimes be more or less biased, but nonetheless cannot be regarded as disinformation). All the ads that contained verifiable facts were fact-checked through news media and other information sources.

The second variable is linked to the main topics of the ads, which were classified in the following categories, designed on the basis of a preliminary study of the corpus: 1 ) employment; 2) party promotion; 3) Spain's cohesion (Catalan independence issue, glorification of the country); 4) social policy; 5) economic policy; 6) feminism; 7) pacts, coalitions and surveys; 8) education and science; 9) environment; 10) democratic quality (corruption); 11) empty Spain (referring to the depopulation of rural areas in the interior); 12) international policy; 13) immigration; 14) infrastructure; and 15) others.

Different teams, each formed by two of the authors of the research, coded each variable. Inter-rater reliability was evaluated using Krippendorff's alpha, obtaining acceptable values for the (dis)information $(\alpha=0.808)$ and topic $(\alpha=0.904)$ variables.

\section{Results}

\subsection{Use of Disinformation}

The presence of disinformation in the electoral propaganda distributed on Facebook by the five main Spanish political parties during the two 2019 general election campaigns was, as can be seen from the data, negligible (see Table 2). There were few occasions on which disinformation appeared in the ads' copy, either as a technique of persuasion or as a complaint.

As can be observed, the vast majority of the ads fell into the first category: they contained phrases that generically appealed to the electorate, attempted to drum up support for the political party in question or set out the party's electoral proposals, the veracity of which cannot be verified, of course, until the party is in a position to implement them either by forming a government or by being able to exert political influence. Of the total number of ads posted, $83.71 \%$ (78.03\% when including the VIAs) fell into this category.

Regarding the ads that included potentially verifiable claims, most of them were accurate or based on real- ity, thus being closer to propaganda discourse than to disinformation. Of the total number of ads, $14.22 \%$ (rising to $20.14 \%$, when including the VIAs) belonged to this category.

All of which means that only $2 \%$ of the ads contained disinformation. This is by no means a negligible proportion, but it does indicate that it is not a technique applied by Spanish political parties across the board, neither as a discursive device to report being victims of disinformation operations ( 12 ads in total) nor as examples of disinformation per se (292 ads, $1.99 \%$ of the total).

\subsection{Disinformation by Party}

Table 3 shows the distribution by party (in both election campaigns) of the different categories used here to detect disinformation or its absence. As before, a distinction can be drawn between the VIAs and the total number of ads posted. It can be seen that the incidence of disinformation parameters was minimal in general and non-existent in the case of IU and the PSOE. The latter developed a campaign focusing on the formulation of electoral proposals or campaign slogans, which did not even include facts that could be checked or verified.

In the main, Ciudadanos was the party posting the highest number of ads containing elements of disinformation, while the PP, Podemos and VOX did so to a lesser extent. Only these last two parties posted ads reporting alleged disinformation practices against them. Table 4 shows the incidence of disinformation in the relative percentage of each party and the corpus as a whole.

Podemos reported disinformation campaigns against it in three different ads. The first recommended a twominute video explaining how "the state's rotten apples" (Podemos, 2019) were intriguing against the party and its leader, Pablo Iglesias, focusing on the alleged manoeuvres of the Ministry of the Interior controlled at the time by Jorge Fernández Díaz (PP), which in theory were being silenced by the media and the powers that be: political institutions, economic elites and members of the judiciary and law enforcement agencies. This same line of argument was deployed in the other two ads, one of which commented on the party's intention not to "spend hours talking to media outlets owned by banks" (Podemos, 2019), while the other invited readers to receive the party's information directly on their cell phones to avoid "fake news against Podemos" (Podemos, 2019).

Table 2. Overall results of the disinformation analysis.

\begin{tabular}{lcrrr}
\hline Disinformation & No. VIAs & \% VIAs & Total no. ads & \% Total ads \\
\hline Does not contain facts & 1,360 & $78.03 \%$ & 12,292 & $83.71 \%$ \\
Reports disinformation & 11 & $0.63 \%$ & 12 & $0.08 \%$ \\
Contains disinformation & 21 & $1.20 \%$ & 292 & $1.99 \%$ \\
Contains facts (not disinformation) & 351 & $20.14 \%$ & 2,088 & $14.22 \%$ \\
\hline Total & 1,743 & $100.00 \%$ & 14,684 & $100.00 \%$ \\
\hline
\end{tabular}


Table 3. Distribution of the disinformation variable by party (\%).

\begin{tabular}{lccllllll}
\hline & & & & & & & \multicolumn{2}{c}{$\begin{array}{c}\text { Contains facts } \\
\text { (not disinformation) }\end{array}$} \\
\cline { 2 - 10 } Party & DIAs & Total & VIAs & Total & VIAs & Total & VIAs & Total \\
\hline Ciudadanos & 10.96 & 46.84 & 0 & 0 & 0.70 & 1.89 & 2.58 & 9.57 \\
IU & 0.69 & 0.11 & 0 & 0 & 0 & 0 & 0.11 & 0.01 \\
PP & 30.75 & 26.65 & 0 & 0 & 0.23 & 0.06 & 14.17 & 4.05 \\
Podemos & 12.97 & 5.69 & 0.34 & 0.04 & 0.06 & 0.02 & 3.10 & 0.54 \\
PSOE & 22.38 & 4.23 & 0 & 0 & 0 & 0 & 0 & 0 \\
VOX & 0.29 & 0.20 & 0.29 & 0.04 & 0.11 & 0.02 & 0.17 & 0.04 \\
\hline Total & 78.03 & 83.71 & 0.63 & 0.08 & 1.20 & 1.99 & 20.14 & 14.22 \\
\hline
\end{tabular}

Regarding VOX, the high proportion of VIAs (33\%, albeit accounting for a scant proportion of the total number of ads and therefore not representative) in which this party presented itself as a victim of disinformation is noteworthy. In all cases, the party used the same text"At VOX we play fair, we do not use the left's black propaganda techniques or spread hoaxes as others do" (VOX, 2019)-together with an image corresponding to the main message, in an attempt to counter calls for tactical voting, namely that voting for VOX in most provinces meant giving seats to the PSOE or Podemos.

When the data in this category is crossed with the thematic classification (see Table 5), it can be seen that Podemos reported disinformation about issues pertaining to democratic quality and party promotion, whereas VOX, as well as mentioning the same topics, also referred to the cohesion of Spain and the environment. Likewise, considering the difference between the VIAs and the total, it can be observed that this kind of message was not amplified (i.e., repeated in the corpus) and that it was a marginal issue.

\subsection{Ads with Disinformation}

The incidence of ads incorporating elements of disinformation is shown in Table 6. The parties that resorted most to this kind of discourse were VOX (13.33\% of the total number of VIAs) and Ciudadanos (5.6\%). Whereas Podemos and the PP were the two parties that posted this type of message a lot less frequently.

As to the PP, there was hardly any disinformation in its ads. Instead, the party chose to include information that best contrasted its management with that of the Sánchez government (PSOE). For example, in those provinces with rising unemployment rates, it was Sánchez's fault; in those where jobs were being created, it was thanks to

Table 4. Reports of cases of disinformation against parties (\%).

\begin{tabular}{llcc}
\hline Party & VIAs & VIAs & $\begin{array}{c}\text { Total } \\
(\mathrm{n}=1,743)\end{array}$ \\
\hline Ciudadanos & 0 & 0 & 0 \\
IU & 0 & 0 & 0 \\
PP & 0 & 0 & 0 \\
Podemos & 2.09 & $0.34,684)$ & 0.04 \\
PSOE & 0 & 0 & 0 \\
VOX & 33.33 & 0.29 & 0.04 \\
\hline Total & & 0.63 & 0.08 \\
\hline
\end{tabular}

Table 5. Reports of disinformation classified by party and by topic (\%).

\begin{tabular}{lccccc}
\hline & \multicolumn{3}{c}{ Podemos } & & VOX \\
\cline { 2 - 5 } Theme & VIAs & Total & VIAs & Total & Total \\
\hline Spain's cohesion & 0.00 & 0.00 & 13.33 & 0.01 & 0.01 \\
Democratic quality & 1.05 & 0.02 & 6.67 & 0.01 & 0.03 \\
Environment & 0.00 & 0.00 & 6.67 & 0.01 & 0.01 \\
Party promotion & 1.05 & 0.02 & 6.67 & 0.01 & 0.03 \\
\hline Total & 2.09 & 0.04 & 33.33 & 0.04 & 0.08 \\
\hline
\end{tabular}


the efforts of "everyone," the "entrepreneurs." The same can be said about Podemos. By and large, this party did not cross the line separating an interpretation of reality that was favourable to its interests but fact-based, from disinformation or the dissemination of false information. Both parties posted a single ad that can be regarded as having contained disinformation.

The PP's ad, which was repeated on several occasions, read as follows: "Whenever the PSOE governs, it gives rise $\&$ to uncertainty. Something called risk premium increases $\square$. We all pay for it. Vote for the People's Party \#SafeValue. $\$$ www.ppvalorseguro.es" (Partido Socialista, 2019).

Although Spain's risk premium (the rate of return that a country issuing sovereign bonds has to pay over and above the risk-free rate of return) rose during the PSOE governments (especially in the last years of the Rodríguez Zapatero government), this has been by no means a systematic trend. Indeed, during the first year of the Rajoy government, Spain's risk premium hit a euroera record (Expansión, n.d.).

There was also disinformation in an ad about the wage gap:

If you're a woman, you're paid $22.3 \%$ less than a man for doing the same job. This means that it's like working for FREE for two months of the year. On 28 April, your vote for Unidas Podemos can guarantee equal pay by law. (Podemos, 2019)

On average, women still earn $22.3 \%$ less than men. Be that as it may, this should be qualified. Women do not earn $22.3 \%$ less than men for doing the same job, but, as a rule, men have better-paid jobs. Other similar ads, plus the video accompanying this same ad, did explain this correctly.

Regarding Ciudadanos, its use of disinformation can be directly associated with its often-aggressive discourse. This belligerence, combined with a more varied, sophisticated and segmented discourse than that of the PP, meant that it was more liable to include inaccuracies and fallacies in its ads than the PP, whose ads tended to be more traditional and ingratiating.

One such example can be found in the large number of ads posted by Ciudadanos on occasion of its recruitment of Edmundo Bal, the public prosecutor who was removed from the case against the pro-independence 'procès,' due to his discrepancies with the Government's line of action. Bal had sought a conviction for rebellion versus the accusation of sedition for which the Attorney General's Office pressed and for which the majority of the prosecuted politicians were ultimately condemned. According to these ads, "国Sánchez removed him as a favour to Torra, Rufián and Puigdemont so as to continue in the Moncloa" (Ciudadanos, 2019), something that has yet to be substantiated.

In other ads that, with slight variations, were also repeated, Ciudadanos contended: "While the PP and the PSOE were making a pact with Pujol and ERC, Inés Arrimadas and Albert Rivera were fighting for the freedom and equality of all Spaniards in Catalonia" (Ciudadanos, 2019). However, the last time the PP struck an agreement with Jordi Pujol was in the year 2000. The Catalan leader abandoned active politics in 2003, three years before Ciudadanos appeared on the scene. In short, in this ad, as in the previous one, the truth (the agreements that the PP and the PSOE had brokered with the nationalists in the past) was distorted by mixing it with false or misleading information.

Ciudadanos also posted seven more VIAs that were reported by various media for their misleading content (Sarabia, 2020). These ads were aimed at the Andalusian provinces, except for Cordoba, encouraging the electorate to vote for the party as it was just a few votes away from winning a seat at the expense of Podemos. As the fact-checker Maldita ("La publicidad de Ciudadanos," 2019) pointed out, however, it was impossible for the party to know this and, therefore, to claim:

00 In the province of Huelva, Ciudadanos is 190 votes away from winning a decisive seat at the expense of Podemos. We all want to oust Sánchez from the Moncloa, but in Huelva, voting for Ciudadanos is the best way to achieve this. (Ciudadanos, 2019)

Lastly, despite the party's scant visibility on Facebook, VOX also included disinformation in its ads. In 15 different ads, most of which were integrated into the same VIA, there were elements of disinformation in two. The first read as follows: "The PP, the PSOE and Ciudadanos: different paths, same objectives. Politically, socially and now also linguistically imposing Catalan on the Balearic Islands, with VOX as the only opposition. $\square$ ES \#VOXGenuineOpposition" (VOX, 2019).

From this ad it can be deduced that the PP, the PSOE and Ciudadanos had all voted against VOX to "impose Catalan on the Balearic Islands" (Loureiro, Muro, \& Alonso, 2019). It was indeed a block of amendments proposed by VOX which, according to the law, had to be voted on as a whole. In this block, VOX included some amendments that were acceptable to ideologically like-minded parties (as is the case of language policy) and others that were totally unacceptable to them. This placed those parties in a dilemma, for if they rejected the block of amendments, VOX could claim that they were in cahoots with the left, whereas if they accepted them, the left could contend that they were indistinguishable from VOX. It is something that this party does very often because it knows that the news coverage will, in one way or another, be to its advantage (Loureiro et al., 2019).

Another ad recommended a video of an interview with Santiago Abascal, the leader of VOX, in which he referred to an unaccompanied foreign minor accused of sexually abusing a 10-year-old girl in Calella (Barcelona). Abascal, among other things, stated the following: "An unaccompanied foreign minor sexually abused a 
10-year-old girl. The abuser is now at liberty. With a restraining order not to approach the victim, he will be able to approach others, we imagine" (VOX, 2019). From this statement it can be inferred that the accused had already been sentenced when, in reality, he had been sent to a juvenile facility, under the restraining order not to approach the victim, pending trial ("Detenido un menor," 2019).

Likewise, when viewed from a thematic perspective (see Table 6 and Figure 2) these data reveal the focus of these disinformation messages. In all the categories, the topic of Spain's cohesion, referring to the Catalan independence issue and the glorification of the country, stands out. The subject of democratic quality, relating to corruption, was the second most frequent theme with respect to the dissemination of disinformation.

The most used topics to denounce disinformation were democratic quality and party promotion, normally associated with a recommended information diet, which tended to be the party's own channel.

Concerning the core topics of the ads, it should be stressed that 13 VIAs posted by Ciudadanos about Spain's cohesion or democratic quality corresponded to 228 and 49, respectively, of the total number of ads making up the corpus. Ciudadanos was the party that aired these topics most, while the PP focused on economic policy (two VIAs out of seven), Podemos referred most to feminism (one VIA out of three) and VOX put the accent on 'other subjects' (one VIA out of two). As can be seen in Table 6, Ciudadanos posted most disinformation (1.55\% of $1.99 \%$ ) in the corpus of ads.

\section{Discussion}

This aim of this study had been to analyse the use of disinformation by the leading Spanish political parties in the

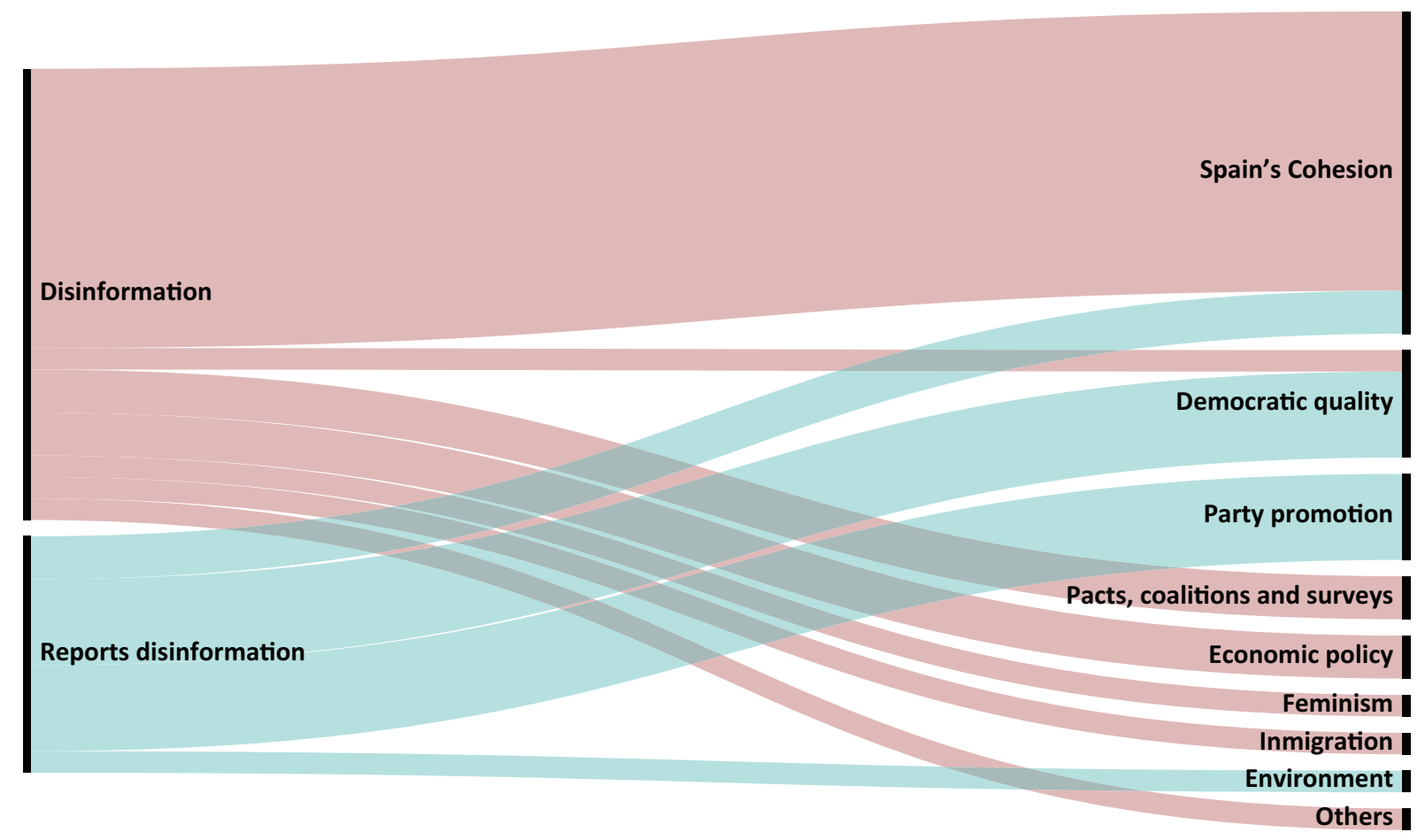

Figure 2. Reporting and use of disinformation by topic.

Table 6. Use of disinformation by political party and by topic (\%).

\begin{tabular}{lcccccccrrr}
\hline & \multicolumn{2}{c}{ Ciudadanos } & \multicolumn{2}{c}{ PP } & \multicolumn{2}{c}{ Podemos } & \multicolumn{2}{c}{ VOX } \\
\cline { 2 - 7 } Topic & VIAs & Total & VIAs & Total & VIAs & Total & VIAs & Total & Total \\
\hline Spain's cohesion & 5.20 & 1.55 & 0.00 & 0.00 & 0.00 & 0.00 & 0.00 & 0.00 & 1.55 \\
Pacts and surveys & 0.00 & 0.00 & 0.25 & 0.01 & 0.00 & 0.00 & 0.00 & 0.00 & 0.01 \\
Others & 0.00 & 0.00 & 0.00 & 0.00 & 0.00 & 0.00 & 6.67 & 0.01 & 0.01 \\
Economic policy & 0.00 & 0.00 & 0.25 & 0.05 & 0.00 & 0.00 & 0.00 & 0.00 & 0.05 \\
Feminism & 0.00 & 0.00 & 0.00 & 0.00 & 0.35 & 0.02 & 0.00 & 0.00 & 0.02 \\
Democratic quality & 0.40 & 0.33 & 0.00 & 0.00 & 0.00 & 0.00 & 0.00 & 0.00 & 0.33 \\
Immigration & 0.00 & 0.00 & 0.00 & 0.00 & 0.00 & 0.00 & 6.67 & 0.01 & 0.01 \\
\hline Total & 5.60 & 1.89 & 0.51 & 0.06 & 0.35 & 0.02 & 13.33 & 0.02 & 1.99 \\
\hline
\end{tabular}


two 2019 general election campaigns. The corpus was extracted from the Facebook Ad Library, which was not available before these elections were held. Therefore, this comprehensive and novel corpus contributes to pave the way for future research on political communication and related computational phenomena (Tufekci, 2015; Woolley \& Howard, 2018).

When performing our analysis on the election campaign ads on Facebook, we were interested in confirming whether or not the Spanish political parties leveraged disinformation tactics identified in previous political processes at an international level (Marwick \& Lewis, 2017) and specifically in targeted advertising on Facebook (Bakir \& McStay, 2018; Gray et al., 2020), to persuade particular sectors of the electorate.

However, the results of our analysis show that the parties' approach was much more conventional (López García, 2016), as it generally copied that of traditional campaigns, focusing on electoral proposals and promises, in which in most cases the bias of the facts narrated did not tend to qualify as falsehood (thus respecting the rules of democracy). Our findings reveal that the Facebook Ad Library per se is not enough to audit disinformation campaigns on social networking sites and that greater efforts should be made in this respect at various levels (Tucker et al., 2018). As a matter of fact, it could be claimed that our research shows that the open and transparent nature of the Facebook Ad Library may be a factor that explains the relatively low percentage of ads in our corpus that included elements of disinformation, because such practices could easily be detected.

The presence of disinformation in the parties' political advertising messages was rather scarce, albeit not negligible. Although they certainly did not put Facebook's capabilities to a widespread use to discriminate, segment or intoxicate the public debate with false or misleading information. Even though we did not perform an ad segmentation analysis (which was beyond the scope of our study), we have shown that in the context of the 2019 general election campaigns disinformation revolved around a highly polarised issue in Spain, as previously identified in similar studies (Stella et al., 2018): The country's cohesion or, more generally, the autonomy of each one of its regions.

As can be deduced from the specific analysis of each party, we have also revealed that there were significant differences between them in terms of their use of advertising. We could establish a dividing line between the traditional parties, in which we have not detected disinformation (PSOE and IU) or to a minimum extent (PP), and the new parties that have emerged as a result of the crisis of the two-party system linked to the recession that began in 2008 (Ciudadanos, Podemos, and VOX).

The discursive approaches of the latter were very different from those of the former. However, at different levels and from various approaches they revealed the two elements of disinformation that we have dealt with here: the political party as a victim and agent of disin- formation. As can be seen from previous election campaigns, it seems that the 'traditional' parties are taking longer to abandon the classic forms of campaigning than their 'new' counterparts (López García, 2016), which shows that, rather than being reduced to the extreme right of the ideological spectrum, there is a large variety of political actors who resort to disinformation tactics (Bennett \& Livingston, 2018).

Finally, our results yet again highlight the difficulties in making a distinction between advertising, propaganda and disinformation. The ads analysed here were similar in that they were publications appearing in the Facebook timeline, which were labelled as advertising (Tandoc et al., 2018) and promoted by a specific political organisation to persuade the electorate (Molina et al., 2019). The partisan rhetoric of these ads sometimes included elements of disinformation and incorrect data to win votes. Although they should be understood as being integrated in a complex system (Marwick \& Lewis, 2017) in which misleading information reflects different discourses, ad and distribution strategies and authors. The phenomenon of disinformation is inextricably linked to the analysis of the messages of networked politicians (Marwick \& Lewis, 2017), even when they take the shape of ads that are freely accessible to the public on the platform attempting to audit them.

At a theoretical level, we concur with those authors who stress the epistemological difference between disinformation and fake news (Bennett \& Livingston, 2018; Ireton \& Posetti, 2018). The centrality of fake news in the analysis of political processes may lead to an oversimplification of content deliberately intended to spread disinformation and the actors disseminating it. Our empirical findings show that disinformation is not always produced and distributed by the media and is indeed a propaganda tool (Benkler et al., 2018; Martin, 1982). Internet technologies have provided a new setting for understanding the tactics implemented by political parties to influence public opinion, which not only include ads containing false information, but also bots, polarised groups on social networking sites, media manipulation and even the regular use of social media by political leaders. Future research should approach these phenomena holistically so as to gain a better understanding of disinformation strategies and a more accurate perspective of the links between disinformation and propaganda in contemporary politics. For example, it would be interesting to monitor not only the agents-in this case, political parties-but also specific keywords or topics that are shaping a more complex information landscape.

\section{Acknowledgments}

This research has been carried out in the framework of the project entitled "Strategies, agendas and discourse in electoral cybercampaigns: media and citizens" (CSO2016-77331-C2-1-R), of the research group Mediaflows. The corresponding author would like to 
thank the Spanish National Employment Institute (SEPE) for the unemployment benefits that have made it possible to complete the manuscript in its last stage. Finally, the authors are grateful to Exponentia CIO Juan Besari for providing the appropriate hardware to carry out the Facebook ad extraction processes.

\section{Conflict of Interests}

The authors declare no conflict of interests.

\section{References}

Bakir, V., \& McStay, A. (2018). Fake news and the economy of emotions: Problems, causes, solutions. Digital Journalism, 6(2), 154-175. https://doi.org/ 10.1080/21670811.2017.1345645

Bastos, M., \& Mercea, D. (2018). The public accountability of social platforms: Lessons from a study on bots and trolls in the Brexit campaign. Philosophical Transactions of Royal Society, 376(2128), 1-12. https:// doi.org/10.1098/rsta.2018.0003

Benkler, Y., Faris, R., \& Roberts, H. (2018). Network propaganda: Manipulation, disinformation, and radicalization in American politics. Oxford: Oxford University Press.

Bennett, W. L., \& Livingston, S. (2018). The disinformation order: Disruptive communication and the decline of democratic institutions. European Journal of Communication, 33(2), 122-139. https://doi.org/ $10.1177 / 0267323118760317$

Bradshaw, S., \& Howard, P. N. (2019). The global disinformation order: 2019 global inventory of organised social media manipulation. Oxford: Project on Computational Propaganda.

Cervi, L., \& Carrillo-Andrade, A. (2019). Post-truth and disinformation: Using discourse analysis to understand the creation of emotional and rival narratives in Brexit. ComHumanitas: Revista Científica de Comunicación, 10(2), 125-149. https://doi.org/10.31207/ rch.v10i2.207

Ciudadanos. (2019). Facebook ad library. Facebook. Retrieved from https://www.facebook.com/ads/ library/?active_status=all\&ad_type=all\&country=ES \&q=Ciudadanos\&view_all_page_id=74078667754

Detenido un menor tutelado fugado por abusar de una niña de 10 años en Calella [An escaped minor in custody was arrested for abusing a 10 year-oldgirl in Calella]. (2019, November 6). El Periódico. Retrieved from https://www.elperiodico.com/es/ sociedad/20191106/mena-abuso-nina-10-anoscalella-7716463

Dommett, K., \& Power, S. (2019). The political economy of Facebook advertising: Election spending, regulation and targeting online., Political Quarterly, 90(2), 257-265. https://doi.org/10.1111/1467-923X. 12687

Expansión. (n.d.). Prima de riesgo de España 2020 [Risk premium in Spain, 2020]. Expansión. Retrieved from https://datosmacro.expansion.com/prima-riesgo/ espana

Ferrara, E. (2017). Disinformation and social bot operations in the run up to the 2017 French presidential election. First Monday, 22(8). https://doi.org/ 10.5210/fm.v22i8.8005

Gray, J., Bounegru, L., \& Venturini, T. (2020). 'Fake news' as infrastructural uncanny. New Media \& Society, 22(2), 317-341. https://doi.org/10.1177/ 1461444819856912

Hern, A. (2018, November 29). Facebook to require proof that political ads come from UK. The Guardian. Retrieved from https://www.theguardian.com/ technology/2018/nov/29/facebook-to-requireproof-that-political-ads-come-from-uk

Ireton, C., \& Posetti, J. (2018). Journalism, 'fake news' \& disinformation: Handbook for journalism education and training. Paris: Unesco Publishing.

Jack, C. (2017). Lexicon of lies: Terms for problematic information. New York, NY: Data \& Society Research Institute.

Kim, Y. M., Hsu, J., Neiman, D., Kou, C., Bankston, L., Kim, S. Y., . . . Raskutti, G. (2018). The stealth media? Groups and targets behind divisive issue campaigns on Facebook. Political Communication, 35(4), 515-541. https://doi.org/10.1080/10584609. 2018.1476425

Kreiss, D., \& McGregor, S. C. (2018). Technology firms shape political communication: The work of Microsoft, Facebook, Twitter, and Google with campaigns during the 2016 US presidential cycle. Political Communication, 35(2), 155-177. https://doi.org/ 10.1080/10584609.2017.1364814

La publicidad de Ciudadanos en Facebook: No hay datos que avalen que están "a 190 votos" de quitarle un escaño a podemos en Andalucía [Ciudadanos Facebook ads: No data support that they are "190 votes" away from winning a seat at the expense of Podemos in Andalusia]. (2019, April 26). Maldita. Retrieved from https://maldita.es/malditodato/2019/04/26/ la-publicidad-de-ciudadanos-en-facebook-no-haydatos-que-avalen-que-estan-a-190-votos-dequitarle-un-escano-a-podemos-en-andalucia

López García, G. (2016). New' vs 'old' leaderships: The campaign of Spanish general elections 2015 on Twitter. Communication \& Society, 29(3), 149-168. https://doi.org/10.15581/003.29.3.149-168

Loureiro, M., Muro, M., \& Alonso, M. (2019, October 8). PP y CS no apoyan la propuesta de Vox para tumbar la inmersión lingüística en Baleares [PP and CS do not support Vox's proposal to veto language immersion in the Balearic Islands]. Libertad Digital. Retrieved from https://www.libertaddigital.com/ espana/politica/2019-10-08/vox-jorge-camposlengua-parlamento-balear-espanol-catalan1276645930

Lukito, J. (2020). Coordinating a multi-platform disinfor- 
mation campaign: Internet Research Agency activity on three U.S. social media platforms, 2015 to 2017. Political Communication, 37(2), 238-255. https://doi. org/10.1080/10584609.2019.1661889

Magallón-Rosa, R. (2019). Unfaking news: Cómo combatir la desinformación [Unfaking news: How to combat disinformation]. Madrid: Ediciones Pirámide.

Martin, J. (1982). Disinformation: An instrumentality in the propaganda arsenal. Political Communication, 2(1), 47-64. https://doi.org/10.1080/10584609. 1982.9962747

Marwick, A., \& Lewis, R. (2017). Media manipulation and disinformation online. New York, NY: Data \& Society Research Institute.

Molina, M. D., Sundar, S. S., Le, T., \& Lee, D. (2019). “Fake news" is not simply false information: A concept explication and taxonomy of online content. American Behavioral Scientist. https://doi.org/10.1177/ 0002764219878224

Nielsen, R. K., \& Graves, L. (2017). “News you don't believe": Audience perspectives on fake news. Oxford: University of Oxford.

Paniagua Rojano, F., Seoane Pérez, F., \& Magallón-Rosa, R. (2020). Anatomía del bulo electoral: La desinformación política durante la campaña del 28-A en España [An anatomy of the electoral hoax: Political disinformation in Spain's 2019 general election campaign]. Revista CIDOB d'Afers Internacionals, 124, 123-145. https://doi.org/10.24241/rcai.2020.124.1. 123

Partido Socialista. (2019). Facebook ad library. Facebook. Retrieved from https://www.facebook.com/ads/ library/?active_status=all\&ad_type=all\&country= ES\&q=PSOE\&view_all_page_id =189318235003

Podemos. (2019). Facebook ad library. Facebook. Retrieved from https://www.facebook.com/ads/ library/?active_status=all\&ad_type=all $\&$ country=ES $\& q=$ Podemos\&view_all_page_id=269212336568846

Ribeiro, F. N., Saha, K., Babaei, M., Henrique, L., Messias, J., Benevenuto, F., . . . Redmiles, E. M. (2019). On microtargeting socially divisive ads: A case study of russia-linked ad campaigns on Facebook. In Proceedings of the conference on fairness, accountability, and transparency (pp. 140-149). New York, NY: Association for Computing Machinery.

Ricard, J., \& Medeiros, J. (2020). Using misinformation as a political weapon: Covid-19 and Bolsonaro in Brazil. The Harvard Kennedy School Misinformation Review, 1(2), 1-6. https://doi.org/10.37016/mr-2020-013

Rodríguez-Fernández, L. (2020). Junk news y “medios de desinformación" en la campaña electoral del $10-\mathrm{N}$ [Junk news and "disinformation media" in the 10-N election campaign]. Revista Mediterránea de Comunicación, 11(2). https://doi.org/10.14198/ MEDCOM2020.11.2.19

Ross, A. S., \& Rivers, D. J. (2018). Discursive deflection: Accusation of "fake news" and the spread of misand disinformation in the tweets of President Trump. Social Media+Society, 4(2), 1-12.

Sarabia, D. (2020). Ciudadanos engañó a los votantes con campañas pagadas en Facebook para llamar al voto con datos falsos [Ciudadanos tricked voters with paid campaigns on Facebook to encourage them to cast their ballot with false information]. El Diario. Retrieved from https://www.eldiario.es/tecnologia/ Ciudadanos-votantes-campanas-pagadasFacebook_0_893811190.html

Sinclair, J. (2016). Advertising and media in the age of the algorithm. International Journal of Communication, 10, 3522-3535.

Stella, M., Ferrara, E., \& De Domenico, M. (2018). Bots sustain and inflate striking opposition in online social systems. PNAS, 115(49), 12435-12440. https://doi. org/10.1073/pnas.1803470115

Tandoc, E. C., Jr., Lim, Z. W., \& Ling, R. (2018). Defining "fake news": A typology of scholarly definitions. Digital Journalism, 6(2), 137-153. https://doi.org/ 10.1080/21670811.2017.1360143

Tucker, J. A., Theocharis, Y., Roberts, M. E., \& Barberá, P. (2018). From liberation to turmoil: Social media and democracy. Journal of Democracy, 28(4), 46-59. https://doi.org/10.1353/jod.2017.0064

Tufekci, Z. (2015). Algorithmic harms beyond Facebook and Google: Emergent challenges of computational agency. Journal on Telecommunications \& High Technology, 13, 203-218.

VOX. (2019). Facebook ad library. Facebook. Retrieved from https://www.facebook.com/ads/library/ ?active_status $=$ all $\&$ ad_type $=$ all $\&$ country $=E S \&$ q=VOX\%20Espa\%C3\%B1a\&view_all_page_ id $=467127060059387$

Woolley, S. C., \& Howard, P. N. (2016). Political communication, computational propaganda, and autonomous agents: Introduction. International Journal of Communication, 10, 4882-4890. https://doi.org/1932-8036/20160005

Woolley, S. C., \& Howard, P. N. (2018). Computational propaganda: Political parties, politicians, and political manipulation on social media. Oxford: Oxford University Press.

\section{About the Authors}

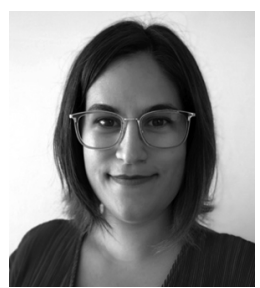

Lorena Cano-Orón is a Postdoctoral Fellow at the University of Valencia. She holds a PhD in Communication and Interculturality with an International Mention (University of Valencia, 2019). She is a Member of the research groups Mediaflows and ScienceFlows. Her lines of research are oriented towards the study of content flows in social networks-in the field of health and political communication-as well as the study of the effects of new technologies from a technopolitical perspective. 


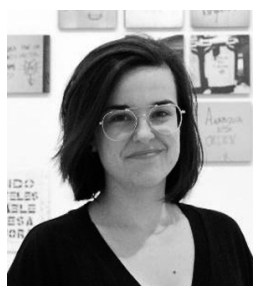

Dafne Calvo is a PhD Candidate in Communication at the University of Valladolid. She has visited research centres in the United States (Northeastern University), Uruguay (University of the Republic) and Mexico (Benemérita Autónoma University of Puebla). Since 2014, she has been a Member of the working team in different competitive research projects at a national level. Her doctoral thesis addresses digital political participation and the free culture movement in Spain.

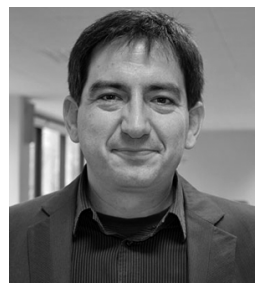

Guillermo López García holds a PhD in Audiovisual Communication (2002) from the University of Valencia, where he has worked as an Associate Professor of Journalism since 2008. Most of his research focuses on political and online communication. He coordinates the R\&D Group Mediaflows, a project focusing on the analysis of communication flows among political parties, the media and citizens in processes of political mobilization. He has authored or edited 12 books and numerous papers and book chapters in scientific publications.

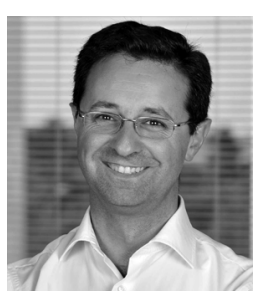

Tomás Baviera is a Senior Lecturer in Marketing at the Universitat Politècnica de València. He holds an MSc in Telecommunication Engineering from the same university, a MA degree in Applied Social Research Methods from the Universitat Autònoma de Barcelona, as well as a PhD in Communication from the Universitat de València. He is a Researcher in the Mediaflows research group, which focuses on political communication during election campaigns. His research interests include digital communication, online marketing and organisational behaviour. 